\title{
DETERMINANTS OF THE DEATH RATE FROM ROBBERY: A DETROIT TIME STUDY
}

\author{
FRANKLIN E. ZIMRING*
}

$\mathbf{R}$ ATES of criminal homicide in the United States, always high in comparison with other developed countries, have increased dramatically since the early 1960 s. The aggregate U.S. homicide rate estimated by the F.B.I. more than doubled during the period 1963-1974, and homicide rates in major urban centers have increased even more substantially. ${ }^{1}$ As the rate of homicide has increased, patterns of criminal homicide have also changed substantially. ${ }^{2}$ National data and studies of individual cities show that while the majority of all killings are still committed by friends or acquaintances of the victim, a substantial and increasing proportion of the "new American homicide" is the outcome of robbery-an event where victim and offender are usually strangers. ${ }^{3}$

This note reports a time series study of robbery killing in Detroit during the 13-year period extending from 1962 through 1974. The Detroit case study is of special significance for two reasons. First, information on robbery rates by weapon is not available for most cities prior to 1974; weaponspecific robbery rates are available in Detroit, making it possible to explore the pattern of weapon-specific death rates over an extended period of time. Second, the increase in robbery killing in Detroit was substantial. Despite a

\section{(C) Franklin E. Zimring, 1977}

This study was supported by PSH Research Grant No. 1 RO 1 MH27575, N.I.M.H., Center for Studies of Crime and Delinquency. Laura Gerard, a third-year student at the University of Chicago Law School, provided valuable research assistance. The Detroit Police Department generously provided the data which made this exercise possible.

* Professor of Law and Director, Center for Studies in Criminal Justice, The University of Chicago.

${ }^{1}$ Compare Federal Bureau of Investigation (F.B.I.), Uniform Crime Reports 1963, at 3, 6-8 with id. 1973, at 6-10. See also Franklin E. Zimring, Firearms and Federal Law: The Gun Control Act of 1968, $4 \mathrm{~J}$. Leg. Studies 133 (1975).

2 See Richard Block \& Franklin E. Zimring, Homicide in Chicago, 1965-1970, $10 \mathrm{~J}$. Res. Crime \& Delinq. 1, 7 (1973). See also Richard Block, Homicide in Chicago: A Nine Year Study (1965-1973), 66 J. Crim. L. \& Crim. 496 (1975) (especially 505-09).

3 See, for example, Richard Block, supra note 2. Parallel studies of Detroit and Atlanta have reported roughly similar findings: Joseph C. Fisher, Homicide in Detroit: The Role of Firearms, 14 Crim. 387 (1976); Robert S. Monford, Ross S. Kazer, Robert A. Feldman, \& Robert R. Stivers, Homicide Trends in Atlanta, 14 Crim. 213 (1976). 
decline in population between 1962 and 1974, the number of police-classified robbery motive killings increased from 15 to 155 per year. This ninefold increase in death rate provides an important opportunity to study the determinants of death rates from robbery. The first section of this note reports our analysis of the data on robbery and robbery killings. The second section addresses some tentative policy conclusions.

I.

Data collection for the Detroit time series analysis was relatively uncomplicated. Information on robberies involving a weapon was retrieved from the archives of the Detroit Police Department for each of the 13 years under study. Individual descriptions of each of the police-nominated robbery killings during the period were excerpted from Detroit police homicide files and forwarded to the Center for Studies in Criminal Justice for analysis. For each killing, data were collected on the lethal weapon, the age, race and sex of the victims, and, where available, of the offenders as well. The essential strategy of the analysis was to mesh data on the incidence of robbery with that of robbery killings to see what can be learned about determinants of death rates related to robbery.

We began the search for an explanation of Detroit's increase in robbery killings by asking whether, and to what extent, the increase in robbery homicide is a function of the increase in the number of robberies. Figure 1 sets forth the trends in robbery and robbery killing for the period under study.

During the period under study, the number of robberies increased from about 4200 to slightly over twenty thousand; the number of robbery killings increased from 15 to 155 . The increase in frequency of police-reported robberies is an insufficient explanation of the increase in death rate for two reasons. First, a fourfold increase in robbery cannot, a priori, completely explain a ninefold increase in robbery killing. Second, while the relationship between robbery and robbery killing trends is close through the period 1962 through 1970, the two trends diverge after 1971 in a fairly dramatic fashion. This divergence may be partially explained as resulting from a decreasing proportion of nonfatal robberies being reported to or by the police after 1970 . Because victim survey data are not available over most of the study period, the precise impact of differential underreportage cannot be investigated. ${ }^{4}$

\footnotetext{
4 The National Opinion Research Center (N.O.R.C.) conducted the first national sample victim field survey in 1966. The U.S. Bureau of the Census initiated a series of national and city level victim survey studies in 1972 and has reported these findings for 26 cities. The 1966 N.O.R.C. study differed from the census studies not only in that it was a national sample, but in design and instrumentation. Data from the N.O.R.C. survey is published in U.S. President's Comm'n on Law Enforcement \& Ad. Just., The Challenge of Crime in a Free Society ch. 2 (1967). The census data available for Detroit victimization is based on field interviews con-
} 


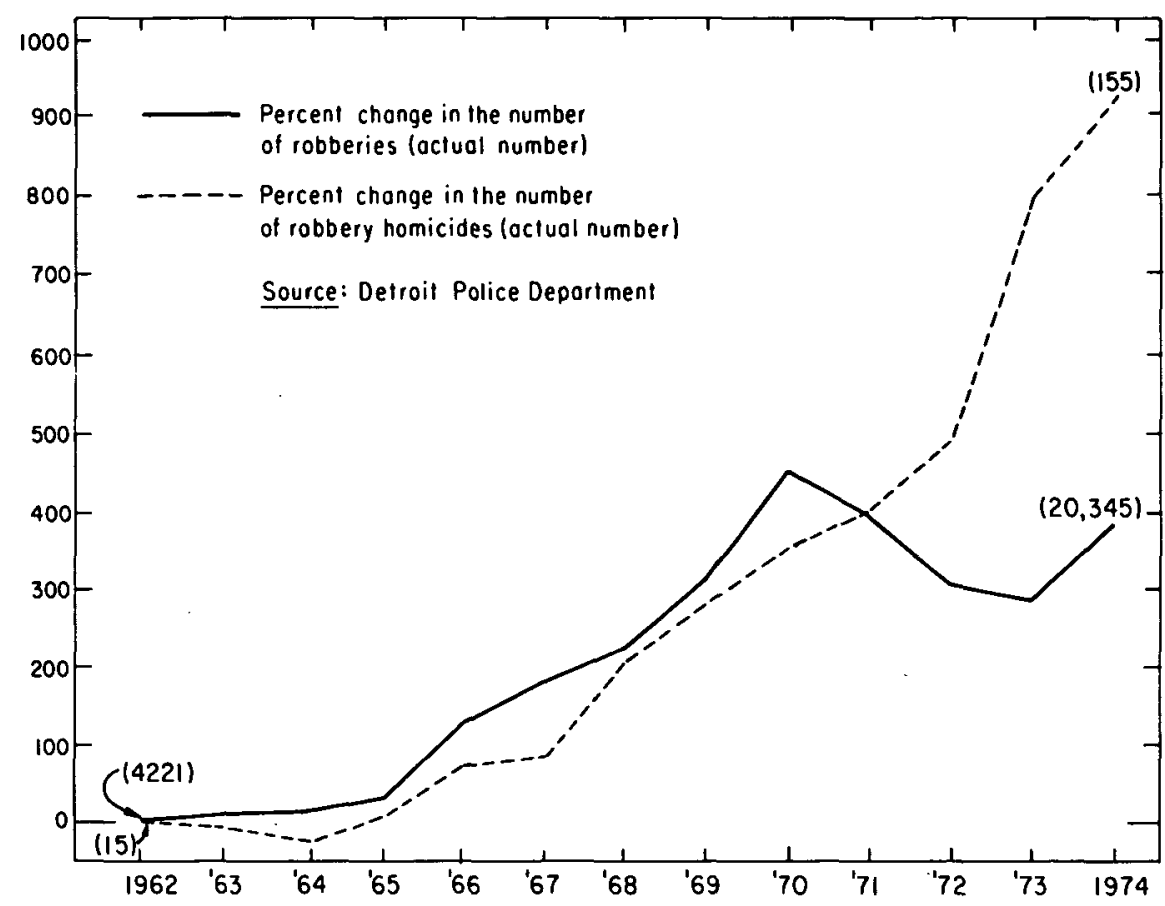

FIGURE 1

Trends in Robbery and Robbery Killing, Detroit, 1962-1974

ducted in 1973 and 1975, well into the time period under study. See U.S. Dep't Just., L.E.A.A., Criminal Victimization Surveys in the Nation's Five Largest Cities (1975); id., Criminal Victimization Surveys: A Comparison of 1972 and 1974 Findings (1976). Linda R. Murphy of the Demographic Survey Division of the U.S. Bureau of the Census provided supplemental data.

When the 1973 and 1975 victim answers about whether the incident was reported to the police are compared, no clear pattern emerges in the noncommercial sample, the only sample for which comparative data are available, as shown in the following table:

Percentage of Robberies Reported to Police, By Weapon, 1972 and 1975 InTerviews

\begin{tabular}{lcccc}
\hline & & & Other & No \\
1975 & Gun & Knife & Weapon & Weapon \\
1973 & $73(273)$ & $60(134)$ & $53(68)$ & $46(215)$ \\
& $76(225)$ & $53(119)$ & $59(54)$ & $46(210)$ \\
& & & Chi Square, 1.00 \\
& & df 3, N.S., $<.05$
\end{tabular}

There is no significant difference between reporting rate by weapon between the two years. To test whether trends were the same in the official and victim soundings, we compared the growth in victim-reported incidents in the sample with the growth in police reported robbery. The victim survey sample reported a $14 \%$ increase between the two surveys, compared to an $18 \%$ increase between the 1972 and 1974 police reports. 
A necessary correlate of the fact that increased robbery volume does not account for the increased number of robbery deaths is that the death rate per 1000 robberies in Detroit has been increasing, as seen in Figure 2.

Figure 2 illustrates the close fit in robbery and robbery killing trends prior to 1971 by showing an essentially stable death rate per 1000 robberies with only minor fluctuations. The divergence after 1970 in the two-trend patterns is reflected in the increase in death rate per 1000 reported robberies to a level in the 1973-74 period that is approximately double the earlier noted values.

There are two points to be made about the relationship between robbery volume and the death rate from robbery in Detroit. First, the increase in robbery volume alone accounts for less than half of the noted variance in robbery killing. This can be confirmed by taking the 1962 death rate (3.57 per thousand) and multiplying it by the 1974 volume of robberies $(20,300)$; the result of this procedure is an estimated 72 robbery killings, less than half the 1974 total, representing $40 \%$ of the increase in deaths.

The second way of looking at the impact of robbery volume is also important: given that the death rate from robbery has risen, increases in robbery volume have a powerful effect on the number of robbery killings. Thus, if



Death Rate Per 1000 Reported Robberies, Detroit, 1962-1974 
the volume of robbery had remained constant and the death rate from robbery had increased to its 1974 level ( 7.6 per thousand), only 28 robbery killings would have occurred, less than a fifth of the actual number of 1974 killings. The explosive growth in robbery killing is thus a function of the interaction between increases in the death rate and robbery volume. The remainder of this section attempts to explore this relationship further through a weapon-specific analysis of death rates and a somewhat more adventuresome correlational analysis of the relationship between weapon mix and death rate.

\section{Weapon-Specific Death Rates}

The availability and use of weapons can affect the death rate from robberies in at least three ways. First, if deadly weapons are selected for robberies, and an injury does occur, the use of more lethal instruments will increase the number of fatal injuries. The plausibility of this hypothesis can be illustrated by the fact that guns accounted for $72 \%$ of all robbery killings in 1974 but only $42 \%$ of all robberies reported by the police. A second possible "weapon" effect is that the availability of deadly weapons makes robbery relatively easy and thus increases the rate of robbery and the total death rate from robbery. A third possible weapon effect is that the availability of deadly weapons decreases victim resistance and thus decreases the number of resistance-motivated robbery killings. The time series method and data are not sufficiently rich to directly address all three hypotheses, but provide interesting observations that may be relevant to each.

Table 1 sets out the trend in robbery by weapon for the years under study.

The data in Table 1 include both fatal and nonfatal robberies. The table shows that gun robbery increased ninefold during the thirteen-year span, compared to less dramatic increases for other types of robbery. The impact of this shift in weapon type on death rate from robbery can be traced by determining the weapon-specific death rate from robbery over the study period. This data is provided in Figures 3-6.

Death rates from gun robbery are consistently higher than those reported for other methods of attack. Gun robbery death rates also increase during the period studied. Death rates from knife robbery are also relatively high but far less stable in trend. Strong-arm robbery (no weapon) has a persistently low and unstable death rate, with no apparent trend. Death rates in the residual category of "other weapon" fluctuate wildly with most of the higher values in more recent years.

The data in Figures 3-6 can be both used and questioned. Our first use of the data is to determine how much of the increase in robbery death rate can be explained as a function of the increase in robbery combined with the change in weapon pattern. The method used for this estimate is to multiply 


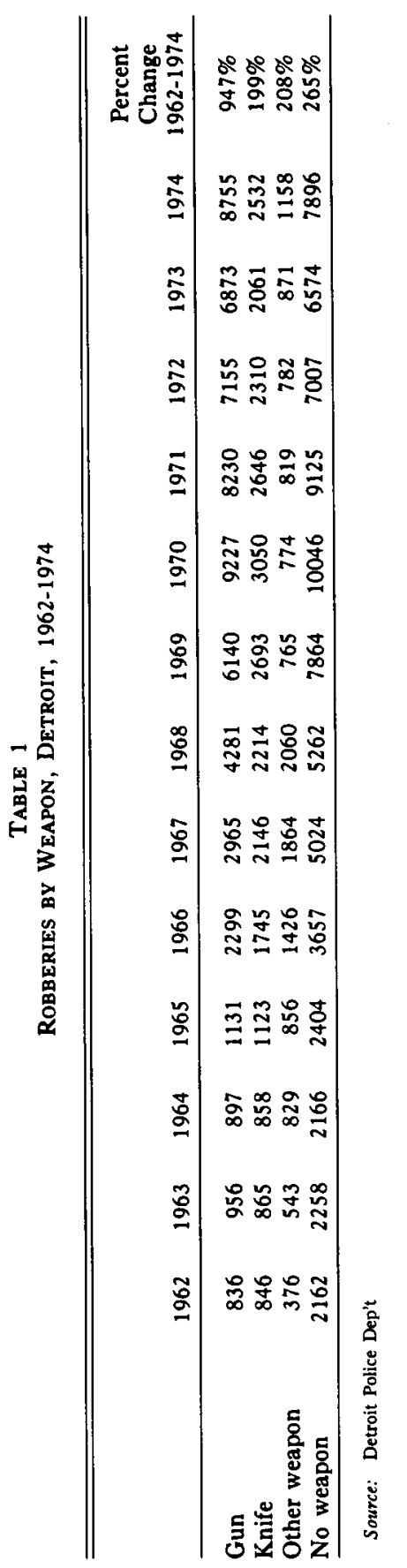




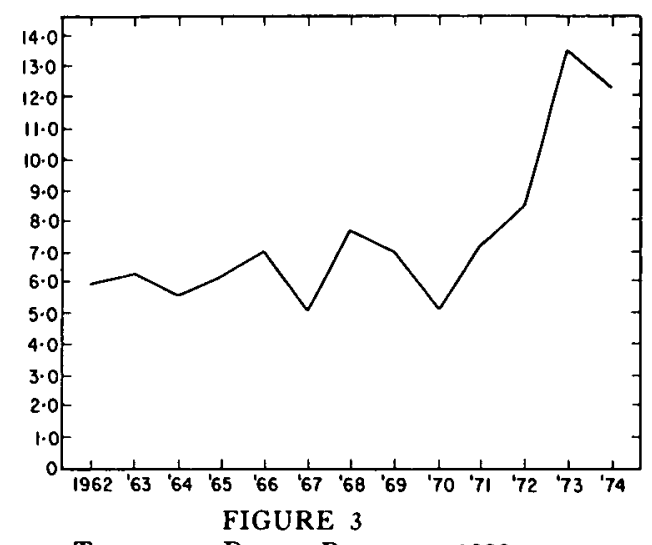

TRENDS IN DEath Rate PER 1000

Gun RoBberies, DetroIT, 1962-74

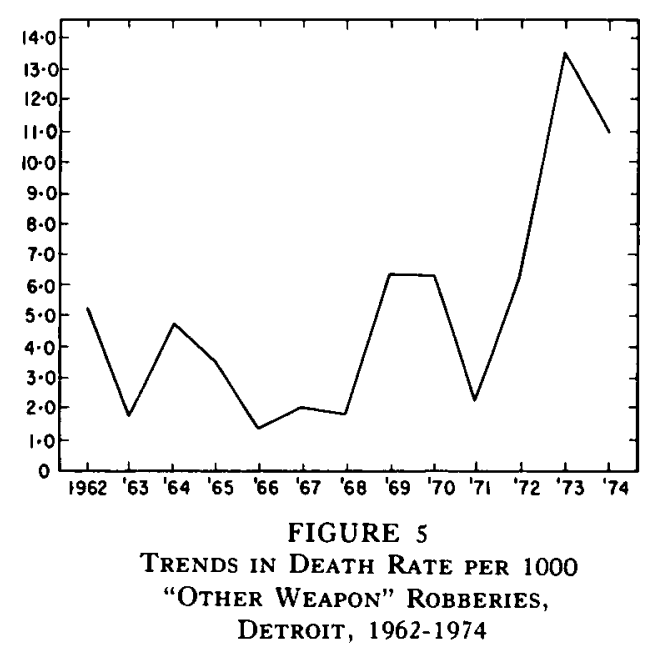

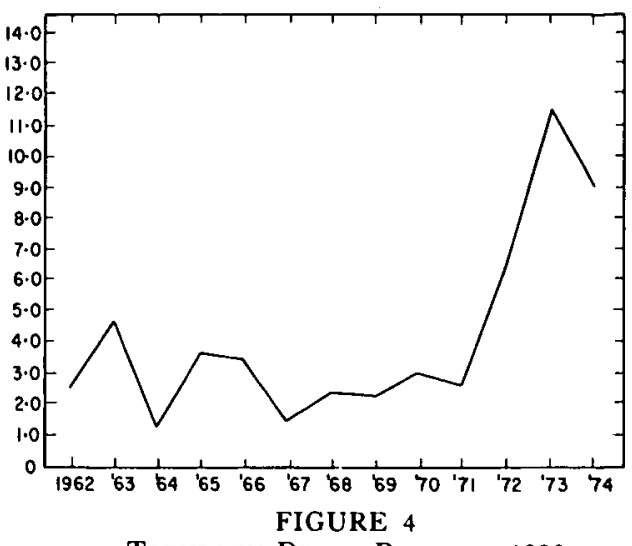

Trends in Death Rate Per 1000 KNIFE RoBberies, DetroIt, 1962-1974

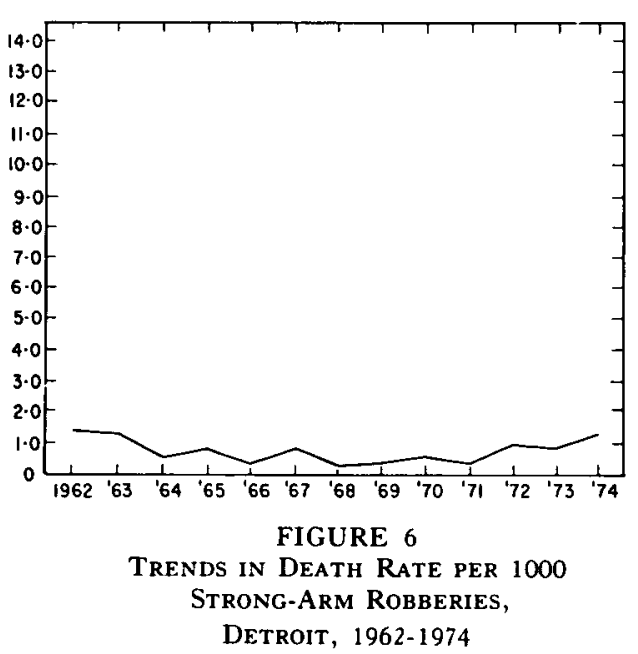

Source: Detroit Police Deportment

the 1974 incidence of each weapon-specific robbery rate by the 1962-63 death rate for that weapon type. The death rate for the beginning years is determined by averaging 1962 and 1963 to provide a more stable baseline death rate. The method predicts a 1974 total of 81 robbery deaths, slightly over half of the actual 1974 total and $47 \%$ of the increase in robbery killings. The 
remaining $53 \%$ of the increase in robbery killing is a function of the increase in weapon-specific death rates derived from police statistics.

The use of police-reported robbery rates raises serious problems in data interpretation. ${ }^{5}$ To the extent that nonreporting of robberies has been increasing over time, the increase in robbery death rates could be an artifact of the denominator of the death rate in that weapon-specific robberies reported by the police may be a diminishing fraction of total robberies. Further, there is circumstantial evidence that a larger number of borderline cases were classified as robbery killings after 1971 , because the death rate from gun and knife assault inexplicably fell during the early 1970s, while the death rate from robberies was rising. There is also the difficulty of classifying homicides by motive. ${ }^{6}$ The estimate of death rate is, therefore, an inexact one.

One method of testing the extent to which weapon choice, as opposed to other factors, influences death rates is to ask whether the frequency of a particular weapon use in robbery predicts the death rate from that weapon. Table 2 reports the zero order correlation between the number of robberies committed with each type of weapon and the number of robbery killings attributable to that weapon in each year under study.

The relationship between total number of robberies and total number of associated deaths is strong during the period studied, but disaggregation by weapon type reveals that the most consistent relationship is between gun robbery rates and the level of firearm robbery killings. The smaller relationships between knife robberies and knife robbery killings suggest that reporting and motive classification difficulties are not merely theoretical problems in interpreting these data, although the smaller number of knife robberies might produce instability more often than the high volume of gun robberies and robbềry killings. An obvious method of examining this issue further would be to merge a number of cities into a single time series of robberies and robbery killings. Unfortunately, if police classification practices vary from city to city, such a procedure would aggregate dissimilar observations.

\footnotetext{
5 See, for example, U.S. President's Comm'n, supra note 4, at ch. 2.

${ }^{6}$ In 1974, for example, 173 killings (65\% committed with firearms) were listed as "motive unknown" by the Detroit Police Department. The level of "motive unknown" killings has been increasing faster than the total homicide rate in Detroit and a number of other cities. The relative ease with which killings between close associates can be cleared by the police suggests that such killings are more likely to involve a victim and offender who are not closely related prior to the lethal act. However, the proportion of "motive unknown" killings that are robbery motivated is not obvious. Clearly, the margin of error in estimating robbery death rates grows more substantial as the number of unknown motive killings increases.
} 
TABLE 2

Relationship Between Frequency of Robbery and Number of Robbery Deaths by WEAPON, Detroit, 1962-1974

\begin{tabular}{lcc}
\hline \hline & Correlation & Significance \\
\hline Gun & .86 & $\mathrm{p}<.001$ \\
Knife & .46 & Not Significant at $\mathrm{p}<.05$ \\
Other weapons & .09 & Not Significant at $\mathrm{p}<.05$ \\
No weapon & .51 & Not Significant at $\mathrm{p}<.05$ \\
Total & .77 & $\mathrm{p}<.01$ \\
\hline
\end{tabular}

Source: Detroit Police Dep't

\section{Estimating Differences in Weapon Dangerousness}

The reported death rate from gun robbery is higher than that for other weapons, but not as substantial as other data or the correlation between gun use and total death rate would suggest. ${ }^{7}$ One reason for this finding may be that gun robberies are more frequently reported. Table 3 tests this hypothesis by comparing police and victim survey robberies in Detroit by weapon for 1972 , a year where both data sets are available.

The sample of victim survey robberies is small, but the difference in weapon use has been noted in other cities. ${ }^{8}$ The impact of this apparent difference in reporting robbery by weapon on estimating death rate differences is substantial. Using 1972 police robbery statistics, guns are 1.31 times more deadly per 1000 robberies than knives. Using the police data on deaths, and estimating the relative frequency of gun vs. knife robbery from the victim survey ( 7 to 3 guns as opposed to the officially reported 3 to 1 ) the gun appears to be 2.10 times as dangerous when used in an armed robbery. The same correction techniques estimate gun robberies to be 2.76 times as deadly as "other weapon" robberies and 11.06 times as deadly as strong-arm robbery. 9

7 See the discussion accompanying note 9 infra, and the correlational data reported at pp. 19-21 infra. The victims surveyed in Detroit reported a higher rate of police notification for gun robbery than for other weapon categories.

${ }^{8}$ Preliminary data from a cross-sectional study of robbery in 1974 in 16 cities indicate not only that victim-reported robberies are a lower percentage gun than police reported robberies, but the correlation between the police-reported percentage gun and victim reported percentage gun is a very modest .4. This comparison is based on incomplete victim data, because commercial victim surveys are not yet available for analysis. The data is from unpublished supplementary material provided by local police depts to the Uniform Crime Reporting Section of the F.B.I.

${ }^{9}$ Using victimization data, see supra note 4 , underreporting can be corrected but no specific death rate can be estimated. The data for "other weapon" robberies will be used as an example of the methodology, which is as follows:

Step 1. The deaths (reported by the Detroit Police Department) for "other weapon" robberies are expressed in terms of the percentage of "other weapon" and "gun" deaths $(5 / 61+5=$ $7.6 \%$ ) for 1972 . 
TABLE 3

Percentage of Police- and Victim-Reported Robbery by Weapon Type, Detroit, 1972

\begin{tabular}{lrc}
\hline \hline & Police* & Victim** \\
\hline Gun & 41.3 & 37.3 \\
Knife & 13.4 & 16.8 \\
Other weapon & 4.5 & 6.9 \\
No weapon & 40.8 & 39.0 \\
\hline
\end{tabular}

Source: Detroit Police Dep't, U.S. Census data provided by Dep't Just., L.E.A.A.

* Fatal robberies deleted to create comparability.

** Detroit individuals interviewed between January and March, 1973, meshed with a weighted sample of victim-reported commercial robberies.

\section{A Correlational Approach to Robbery Rates}

The preceding analysis can directly address only one of the three hypotheses about the influence of gun availability on rates of robbery. More speculative methods of inquiry are needed to address the other two hypotheses with these data. Specifically, one can use the percentage of all robberies involving guns as a measure of firearms availability for robbery and test it against rates of robbery and robbery killing. The first query is a supplemental method of estimating the extent to which gun use influences the death rate from robbery; the specific analysis is the relationship between the percentage of all robberies committed by guns and the death rate per thousand total robberies.

Over the period under study, the correlation between percent of total robberies involving a gun and robbery death rates was $.68,{ }^{10}$ suggesting a high correlation between total robbery death rates and the percentage of all robberies attributable to guns. An initial caution is warranted, however, concerning the strength of the relationship and the nature of the correlation. The period studied involved an almost uninterrupted increase in the percentage of robberies due to firearms and in robbery deaths. Despite the fact that there is independent evidence implicating firearms as a predictor of death rates, the statistical association between percent of all robberies due to firearms and robbery death rates is subject to question because there is no

Step 2. That percentage is then divided by the percentage that "other weapon" robberies represents of "other weapon" and "gun" robberies $(2977 /(13223+2977)=18.4 \%)$ estimated in the victimization survey $(7.6 / 18.4=.41)$.

Step 3. Steps 1 and 2 are repeated for "gun" deaths and robberies. The comparable "gun" percentages are found by subtracting the "other weapon" percentages from 100. The parallel gun percentages are $92.4(100-7.6)$ and $81.6(100-18.4)$. After dividing the former by the latter, which yields 1.13 , steps 1 and 2 have been duplicated for "guns".

Step 4. The final ratios derived from gun and other weapon $(1.13 / .41=2.76)$ are the basis for estimating the degree to which guns are more lethal than "other weapons".

10 Significant at $\mathrm{p}<.01$. 
basis for controlling for the independent effect of the passage of time, and all that the passage of time may mean, in exploring the relationship. This problem is compounded by the possibility that the "percentage gun" measure over time reflects not only gun availability but also changing patterns of robbery reporting to and by police. Since victims and police are least likely to report less serious robberies, ${ }^{11}$ the percentage of robberies attributed to firearms in official statistics would tend to increase as the percentage of all robberies reported to the police decreases. If the percentage of robberies not reported increases as the volume of robbery increases, the correlation between relative gun use and robbery rate may reflect, in part, the relationship between robbery volume and the tendency to not report.

Our inability to control for all of the changes in Detroit that are attributable to the passage of time is a chronic problem in correlational analysis, unless other determinants of robbery rates can be identified and measured. Since so little is known about robbery, particularly during the period under study, a more refined model seems infeasible.

Notwithstanding the difficulties of correlational analysis, the relationship between the percentage of all robberies attributable to guns and total robbery rates is worthy of note. During the thirteen years observed, the relationship between percentage of total robberies attributable to guns and total robbery rates was $.96 .{ }^{12}$ The correlation is consistent with the hypothesis that firearm availability and use increase rates of robbery, but it is a preliminary indication at best.

The noted associations also suggest that any tendency for increased firearm use to decrease victim resistance and thus death risk is overwhelmed by the larger impact of increased firearm use. Again, the reader must be cautioned that the steady increase in both robbery rates and the percentage role of firearms include the effects of time as well as the effects of firearms use.

\section{Race, Victimization and Offensivity}

While most homicide is intraracial in character, the common perception of robbery and robbery homicide is of an event that involves a black offender and a white victim. In fact, recent studies establish that urban blacks run higher risks than urban whites of being involved in robbery incidents. ${ }^{13}$ The data we have on robbery killing shows an interesting temporal pattern. Figure 7 presents data on the racial concentration of the city of Detroit,

\footnotetext{
1 See the weapon-specific reporting data supra note 4.

12 Significant at $\mathrm{p}<.001$.

${ }^{13}$ See Philip J. Cook, A Strategic Choice Analysis of Robbery in Sample Surveys of the Victims of Crime 173, 175-77 (W. Skogan ed. 1976).
} 


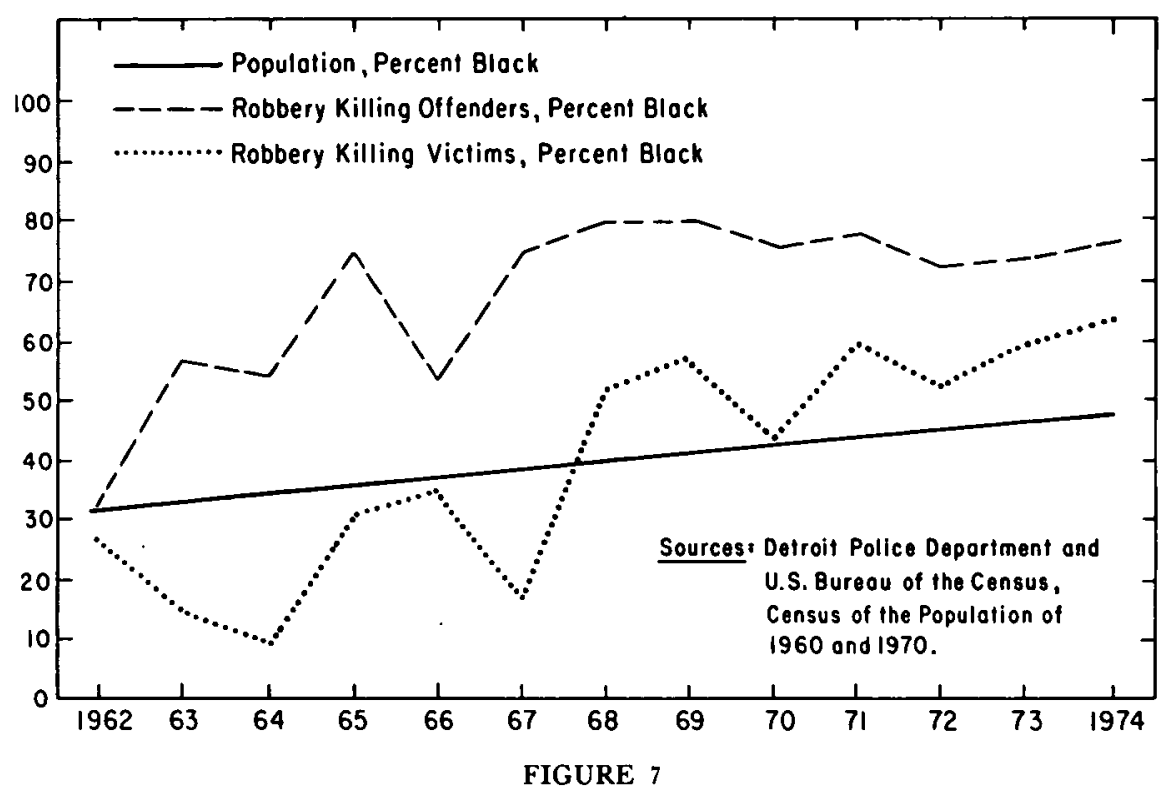

Racial Concentration of Detroit Population, Robbery Killing First Offenders, RobBery Killing Victims, Detroit, 1962-1974

robbery killing offenders, and robbery killing victims. For purposes of economy in presentation, the graph shows by year the percentage of all residents, all first offenders, ${ }^{14}$ and all robbery killing victims who are black.

In the early years of the study period, the interracial stereotype of robbery killing is confirmed by the data. Over time, with a rather abrupt change in the late 1960s, the stereotype was reversed. By 1970 the majority of all robbery killing victims are black with a concentration reaching 64 percent in 1974. A shift in the racial mix of the city's population accounts, in part, for this change, but cannot explain either the extent of racial concentration in the latter years or the suddenness of the shift in pattern. Some of the pattern may reflect changes in police classification in questionable cases. But since the point of abrupt change is not correlated with any sudden shift in the upward

14 Race data were collected for all robbery offenders but reported for the first offender only to control for the misleading racial characterization that results from any aggregation of total suspects or total arrests in violent crime. Younger offenders, particularly younger black offenders, tend to commit robberies in groups. This fact, together with the younger age profile in urban black vs. white populations, means that counting all offenders will tend to overestimate the extent to which blacks are responsible for violent crimes. Methodologically, counting only the first offender's race assures that each robbery death has the same significance in the table, rather than making the importance of the lethal event turn on the number of offenders involved. 
trend of robbery killing, these data may also demonstrate the extent to which riot-induced psychological segregation was reflected in the increased concentration of crime victimization within Detroit's black community.

\section{AN IMPORTANT UNANSWERED QUESTION}

Before proceeding to a discussion of the possible policy significance of our findings, it is important to emphasize the central mystery of these data-the extremely high death risk associated with robbery when compared to other crimes with property motives. Using police-reported gun robberies as the denominator, slightly more than one out of 100 gun robbery encounters will produce a death. Correcting for underreporting by using the victim survey estimates, the proportion would be approximately one in $100,{ }^{15}$ and this includes some robberies where the "gun" might be a toy or a bluff. Studies using other methods suggest that the robber's physical security is not at risk in anything near this proportion of cases. ${ }^{16} \mathrm{Killing}$ robbery victims to eliminate witnesses seems counterproductive in that clearance rates for robbery killings are higher than the general clearance rate for robberies. ${ }^{17}$ If robbery were a totally instrumental crime, the rational robber would usually desist and find another victim, upon victim resistance or refusal. The high and apparently weapon-related death rate from robbery invites speculation as to whether it is appropriate to consider the robbery event as solely instrumental. This is a question that can only be speculatively addressed on the existing data, but deserves extensive further study. ${ }^{18}$

15 The 1975 victim surveys, supra note 4 , estimate that $73 \%$ of all gun robberies were reported to the police by individuals. The reporting rate for commercial establishments is higher. Assuming a total reporting rate of .75 , the official death rate of 12.3 per thousand is multiplied by .75 to yield a correct estimate of 9.23 per 1000 gun robberies.

${ }^{16}$ Our study of 1222 robberies in Chicago, see notes 17 \& 18 infra, suggests a very modest risk to the robber's physical security. Moreover, the weapon-specific death rates in this study seem inconsistent with a "offender safety" theory of robbery killing: the more deadly the robber's weapon, the higher the probability that he will kill. Intuitively, the more deadly his weapon the greater the balance of terror between offender and victim favors the offender. While this may be balanced off, in part, by heavily armed offenders selecting relatively harder targets for attack, one doubts that the balance is complete. In Detroit during 1974, 16 citizens killed suspected robbery offenders, a rate one-tenth that of killing by robbery offenders. In an additional six cases, the police reported a justifiable killing.

17 The arrest rate per 100 non-fatal robberies was $29 \%$ in a 1975 sample of 1222 robberies in Chicago. For the 48 police classified robbery killings that occurred during the 1975 sample period, the arrest rate was $60 \%$. See note 18 infra.

${ }^{18}$ To supplement the efforts reported in this time study, we are analyzing in detail a representative sample of robberies and robbery killings in Chicago during 1975, and attempting, crosssectionally, to use police and victim survey data to explore the nature of the robbery outcome. Some of the Chicago data will be reported by my colleague, Richard Block, in Violent Crime: Environment, Interaction and Death (forthcoming 1977). My own analysis of this data is still in progress. 
II.

The methods employed in this study are imperfect and must be supplemented with other research strategies. However, the tentative findings invite speculation about the implications of these data for research and public policy.

The weapon effects found in the present study are dramatic; yet, there are no prior studies of weapon effects. Robbery statistics were not even divided into weapon-specific categories until 1974 in the Uniform Crime Reports. When gun robbery is ten or eleven times more likely to result in death than unarmed robbery, weapon-specific robbery rates are a necessary condition to minimally effective crime reporting. ${ }^{19}$ Indeed, from the standpoint of death risk, the contrast between armed and unarmed robbery is as important as the contrast between unarmed robbery and other offenses. In the present study, as Table 2 illustrates, a failure to introduce weapon-specific robbery data would have led observers to conclude that there is a strong and stable relationship between robbery volume and death risk, when no weaponspecific stability exists except for gun robbery. Such aggregation problems are probably common in the statistical study of crime, but no less regrettable because they are numerous.

The increases in weapon-specific death rates are difficult to interpret without longitudinal victim survey data. A substantial portion of the increase could be due to differences in reporting robbery over time, but it is unlikely that differential reporting tells the whole story because gun robbery is reported to the police in most victim-reported robberies. The sharp divergence between the stable gun death rates in the first phase (1962-70) of the study and the escalation of death rate in the second phase (1971-74) may also reflect changing patterns of victim resistance or offender intention. The historical data is not rich enough to address this important topic.

\section{Toward a Criminal LaW of Robbery}

The data are relevant to criminal law in at least three ways. First, they support the distinction made by criminal law both in theory and practice between armed and unarmed robbery. Second, these data call into question the indiscriminate scope of the felony murder rule. Third, they suggest that effective firearms control measures may affect both the frequency and lethality of robbery.

In penal policy, the distinction between armed and unarmed robbery

19 Prior to 1974, the Uniform Crime Reporting Section would divide robberies reported by the police into armed and unarmed categories but place greater emphasis on the robbery category as a unit. Weapon-specific robbery rates were first collected on a one-time experimental basis about seven years ago by the Federal Bureau of Investigation, and became standard reporting procedure in January 1974. 
should be crucial. Despite the fact that robbery without a weapon results in injury more frequently than armed robbery, it seems apparent that two types of behavior which vary by as much as a factor of 10 with regard to death risk do not belong in the same section of a rational penal code. Whether the relevant objective is marginal general deterrence or retribution, the armed robbery presents a distinctive threat entitled to priority in the allocation of penal resources.

While the weapon used is an important element in grading nonlethal robbery, ${ }^{20}$ any death associated with robbery, burglary, arson, or one of a small list of other offenses is typically treated as murder by common law and as first degree murder by statute. ${ }^{21}$ The common law felony murder rule imputes "malice," or the intent to do serious bodily harm (needed to establish murder) to the felon, implied by the intent to commit the felony (armed robbery) whether or not any intention to hurt existed. ${ }^{22}$ Since the robber who performs the lethal act is typically guilty of malice whether or not a felony murder rule exists, the practical significance of the rule is to generate liability for accomplices to felonies for the crime of murder whether or not they concurred in the lethal act. ${ }^{23}$

The logic behind the felony murder rule as a whole has encountered sustained and, in my view, successful criticism. If the rule is intended to deter inherently dangerous felonies, stricter penal treatment of all such inherently dangerous felonies is a more logical approach to that goal than a specialized rule for robberies with lethal outcomes. ${ }^{24}$ If, as argued by $\mathbf{M r}$. Justice Traynor of the California Supreme Court,

The purpose of the felony-murder rule is to deter felons from killing negligently or accidentally by holding them strictly responsible for killings they commit, ${ }^{25}$

it is ironic that the principal application of the rule is to generate liability, not for the killer, but for his coadventurers. ${ }^{26}$

Whatever the stated purpose of the rule, our preliminary data suggest that the long list of felonies usually included in the felony murder rule may, from the standpoint of penal policy, be self-defeating. If robbery deaths are substantially unplanned events, the different death rates observed in this study

20 See, for example, Ill. Rev. Stat. ch. 38, § 18-1 \& 18-2.

21 See, for example, Cal. Penal Code \$§ 187, 189, $190 \& 190.1$, Ill. Rev. Stat. ch. 38, § 9-1(3).

${ }^{22}$ See People v. Washington, 62 Cal. 2d 777, 44 Cal. Rptr. 442, 402 P. 2d 130.

23 Id. at 782.

24 See Oliver Wendell Holmes, Jr., The Common Law 58 (M. Howe ed. 1963).

${ }^{25}$ People v. Washington, supra note 22, at 781.

${ }^{26}$ For data on multiple offenders in robbery homicide see Richard Block \& Franklin E. Zimring, supra note 2, at 7. See also Franklin E. Zimring, Joel Eigen \& Sheila O'Malley, Punishing Homicide in Philadelphia: Perspectives on the Death Penalty, 43 U. Chi. L. Rev. 227, 231-32 (1976). 
suggest that death is an accident that occurs far more frequently when the robber is armed. Removing unarmed robbery and burglary from the coverage of the common law rule would, if any marginal deterrence operates, save lives unless the number of additional unarmed robberies produced by such a shift was ten times as great as the number of cases where the distinction in law persuaded the robber to leave his weapon at home.

The practical impact of any shift in felony murder coverage is difficult to predict and probably minimal. In contrast, any countermeasure that succeeded in reducing gun availability in robbery appears likely to reduce both the number of robberies and the death rate per thousand robberies. Reducing the number of robberies is an obvious social policy goal. Less obvious is the finding that reducing the level of weapon use in robbery can also have a dramatic effect on death risk. Moreover, it is more important from a public health standpoint to reduce gun availability when the rate of predatory crime is high. Detroit, like urban centers throughout the United States, has both a "gun problem" and a "crime problem," and each problem makes the other worse. The data from this study show high variability in both robbery rate and weapon mix; unfortunately, all the variation is in an undesirable direction. It is necessary to begin identifying public policy tools that can operate to produce downward variation. 